\title{
Hepatic Differentiation of Human Embryonic and Induced Pluripotent Stem Cells for Regenerative Medicine
}

\author{
Toshio Miki \\ Eli and Edythe Broad Center for Regenerative Medicine and Stem Cell Research at USC \\ Department of Biochemistry and Molecular Biology, Keck School of Medicine \\ University of Southern California, Los Angeles \\ USA
}

\section{Introduction}

A hepatocyte is one of the most desired cells for regenerative medicine as well as for pharmaco-toxicological testing. Hepatocytes, the parenchymal cells of the liver, possess a wide range of functions, including protein synthesis/storage, detoxification, transformation of carbohydrates, synthesis of cholesterol, bile salts and phospholipids, as well as the excretion of exogenous and endogenous substances (Blouin et al 1977).

The various functions of the liver are essential for the maintenance of the human body and liver failure is often only treatable by organ liver transplantation (OLT). The shortage of donated organs, however, limits this treatment option available to patients. Since the Model for End-Stage Liver Disease and Pediatric End-Stage Liver Disease (MELD/PELD) liver allocation system was introduced in February 2002, the usage of borderline-quality donated livers for OLT has increased (Freeman et al 2002). As a result, the number of patients on waiting lists for OLT has stabilized; however, more than 15,000 patients await OLT annually in the United of States alone (Thuluvath et al 2010).

Hepatocyte transplantation (HT), a cell-replacement therapy for liver disease, could decrease the number of the patients on the waiting list. HT is particularly useful for metabolic liver diseases that do not require whole organ replacement but rather a partial restoration of specific liver metabolic functions (Fox et al 1998, Strom et al 1997). The feasibility and the therapeutic efficacy of HT have been demonstrated in several clinical trials (Strom et al 2006). However, the limited availability of human hepatocytes due to organ shortage prohibits the provision of this promising therapy to patients as a standard option. Human hepatocytes can be isolated from cadaveric livers that are donated but not suitable for OLT (Strom et al 1982). The number of unused donated livers has decreased since the MELD liver allocation system was initiated. This dilemma has led to an urgent demand for developing stem cell-derived functional human hepatocytes as an alternative. Stem cell-derived hepatocytes could also be utilized in artificial liver bio-devices for patients with acute liver failure who may not need the OLT (Gerlach et al 2010, Gerlach et al 2008, Soto-Gutierrez et al 2006a). An unlimited supply of stem cell-derived hepatocytes could facilitate the development of these cell-based therapies for treatment of lifethreatening liver diseases. 
Moreover, these stem cell-derived hepatocytes could be utilized not only for therapeutic applications but also for pharmaco-toxicological testing (Davila et al 2004). It is anticipated that stem cell-derived hepatocytes will be important as in vitro tools for testing drug safety, thereby significantly facilitating drug development. Toxicity assessment for drug development could be conducted with phenotypically and genotypically standardized human hepatocytes. In this regard, genetically homogeneous stem cell-derived hepatocytes would be superior to primary human hepatocytes. Human stem cell-derived hepatocytes would be particularly useful for conducting some infectious disease research as well. As a case in point, hepatocytes derived from animals have been demonstrated to not be useful for the study of human hepatitis virus biology such as HCV (Cai et al 2007).

A number of different stem/progenitor cells have been proposed as an alternative cell source for generation of functional hepatocytes - these include fetal hepatocytes (Suzuki et al 2000), adult hepatic progenitor/stem (epithelial) cells (Alison \& Sarraf 1998), bonemarrow derived-stem cells (Gilchrist \& Plevris 2010), and adipose-derived stem cells (Schaffler \& Buchler 2007). Although the biological potential of fetal hepatocytes and adult hepatic progenitor cells is promising, ethical issues and limited availability hampers development for use in the clinic. Relatively small numbers of stem/progenitor cells would be insufficient for use to generate stem cell-derived hepatocytes in the clinic, particularly for HT, as HT recipients require transplantations of more than a billion cells at a time (Fox et al 1998). Some reports claimed that there was hepatic differentiation of mesenchymal stem cells from adipose tissue or bone marrow. However, the differentiation to functional hepatocytes, remains controversial (Goodell 2003, Wagers \& Weissman 2004). Further research efforts are required to gain consensus for utilizing these adult stem cell-derived hepatocytes in the clinic.

To date, pluripotent stem cells are the most realistic candidate for the generation of stem cellderived hepatocytes. Pluripotent stem cells possess nearly unlimited self-renewal capability in vitro and are able to differentiate into all three germ layers. Human embryonic stem cells (hESCs) are derived from blastocysts (Thomson et al 1998), and several protocols have been published for the differentiation of hESCs to functional hepatocytes. Additionally, recent breakthroughs in the field of induced pluripotent stem (iPS) cell technology (Takahashi \& Yamanaka 2006) have provided yet another promising source to generate stem cell-derived hepatocytes. The human iPS cells may overcome the ethical concerns of utilizing blastocystderived pluripotent stem cell and may provide patient specific immunotype cells so as to avoid the lifelong use of immunosuppressants (Takahashi et al 2007). Disease-specific iPS cells, derived from patients who suffer from various congenital liver diseases, such as alpha1antitrypsin deficiency, familial hypercholesterolemia, and glycogen storage disease, are anticipated to become important tools for studying the mechanisms underlying the pathogenesis of these diseases and investigations of new treatments (Ghodsizadeh et al 2010). Moreover, human iPS-derived hepatocytes would be an unlimited source for materials that are genetically homogeneous for conducting consistent pharmaco-toxicological evaluations. For example, an iPS-derived hepatocyte library could be established based upon single-nucleotide polymorphisms (SNPs) in drug metabolizing enzymes (eg. cytochrome P450s), and this could enable evaluation of drug metabolism with specific SNP-type hepatocytes. These data could be utilized to design personalized therapies for future "made-to-order" medicine (Medine et al 2010).

In this chapter, we describe the developmental progression from a pluripotent stem cell state to hepatocytes and provide an overview of protocols for hepatic differentiation of 
pluripotent stem cells. Enrichment strategies of functional hepatocytes and functional evaluation methodologies are also discussed.

\section{Lessons from liver development}

A reasonable approach to induce hepatic differentiation from pluripotent stem cells is to recapitulate actual embryonic developmental events in vitro. Liver development occurs through a series of cell-to-cell interactions between the embryonic endoderm and its nearby mesoderm (Duncan 2003, Zaret 1996). A number of genes and signaling pathways that are involved in this process have been identified (Lemaigre \& Zaret 2004). Understanding the molecular pathways controlling hepatogenesis is essential in designing protocols for inducing hepatic differentiation in vitro. Although our knowledge of embryonic liver development is based on studies from non-human embryos, it is anticipated that the fundamental processes are similar if not identical to those in human liver development. Studies from mouse, chicken, zebrafish and Xenopus have shown that much of hepatogenesis is evolutionarily conserved (Roberts 2000, Tian \& Meng 2006). Numerous signals are required at each step of hepatogenic development (Lemaigre \& Zaret 2004, Zhao \& Duncan 2005). Here, we review these sequential events - we have divided them into four stages to highlight the crucial cues at each stage for a better understanding of hepatic differentiation protocols that will be described in subsequent sections.

\subsection{Stage 1. Toward definitive endoderm}

The earliest event of organogenesis during mouse embryonic development is gastrulation. At this phase (ED6.5-7.5), the definitive endoderm layer is formed from mesendoderm lineage cells (Tada et al 2005). The process begins with the migration of Brachyury ( $\mathrm{T}$ ) positive cells through the anterior region of the primitive streak and through the Node, located at the anterior-most position of the streak (Vincent et al 2003). It has been shown that signaling by a member of the transforming growth factor (TGF)- $\beta$ superfamily, specifically Nodal, initiates both endoderm and mesoderm formation (Vincent et al 2003). The epidermal growth factor family molecule, Cripto-1/FRL1/cryptic, plays a central role as a co-receptor for Nodal. Nodal/ALK signaling in conjunction with Cripto contributes to generate endoderm precursor cells and for the subsequent specification of definitive endoderm (DE) (Strizzi et al 2005). The duration and magnitude of Nodal signaling influence the specification of mesoderm or endoderm. The physical position of cells relative to the Node also seems to control this specification. Exposure to longer and higher levels of Nodal signaling induce endoderm specification, whereas lower stimulation of Nodal signaling promotes differentiation into the mesoderm (Schier 2003). Nodal signaling targets a core group of endoderm transcription factors genes expression including Sox17, Foxa2 (HNF3 $\beta$ ) (Shen 2007).

\subsection{Stage 2. Influence from cardiogenic mesodermal cells and septum transversum mesenchyme}

Following gastrulation, the definitive endoderm is patterned along the A-P axis into foregut, midgut and hindgut progenitor domains (Dessimoz et al 2006). Morphogenesis forms foregut and hindgut pockets as the endodermal cup is transformed into a gut tube. At ED8 the definitive endoderm cells occupy a portion of the ventral foregut adjacent to the heart. Signaling cues from cardiogenic mesodermal cells such as fibroblast growth factors (FGFs) (Jung et al 1999) and cues from the septum transversum mesenchyme (STM), such as bone 
morphogenic proteins 2 and 4 (BMP2, BMP4) are essential to direct cell fate to a hepatic lineage (Rossi et al 2001). It has been demonstrated that mouse embryonic foregut explants express albumin when co-cultured with cardiac mesoderm (Calmont et al 2006, Rossi et al 2001). Studies using explant systems have shown that the cardiac mesoderm can be replaced by exogenous FGF1 or FGF2 supplementation (Jung et al 1999). BMP signaling is required, but not sufficient, for hepatic induction in explants (Rossi et al 2001).

\subsection{Stage 3. Hepatoblast proliferation}

The domain that eventually becomes the liver moves to the midgut, and the liver diverticulum forms by ED9 (Rifkind et al 1969). By ED9.5, the basal lamina breaks down and hepatoblasts delaminate and migrate into the STM. The liver diverticulum expands into a pronounced liver bud by ED10. The liver bud then undergoes tremendous growth and becomes the major site of fetal hematopoiesis. The massive proliferation and protection from apoptosis are regulated by paracrine signals from adjacent mesenchyme. These signals are including the FGFs, BMPs, Wnts, and the TGF $\beta$ signaling pathways. Hepatocyte Growth Factor (HGF) signaling is also required for hepatoblast migration and proliferation (Birchmeier et al 2003).

Although Wnt/ $\beta$-catenin signaling appears to repress liver fate during earlier endoderm patterning stages of development, $\beta$-catenin has the opposite effect and promotes hepatic growth in the liver bud at this stage (ED10) (McLin et al 2007, Micsenyi et al 2004, Monga et al 2003). Immunohistochemical studies showed TGF- $\beta 3$ expression in the liver bud mesenchyme at ED13.5 (Pelton et al 1991). Similarly, Stenvers et al showed a predominant expression of the TGF- $\beta$ receptor III (TbetaRIII) mRNA in liver at midgestation. They also demonstrated that TbetaRIII gene disruption induced apoptosis in the liver at ED13.5 (Stenvers et al 2003).

\subsection{Stage 4. A bifurcation point to hepatocyte or cholangiocyte}

The differentiation of bi-potential hepatoblasts into hepatocytes or cholangiocytes begins around ED13 of mouse development. Hepatoblasts, adjacent to the portal vein, transform into cuboidal cells, which eventually forms the intrahepatic bile ducts during the prenatal period through the ductal plate remodeling process (Lemaigre 2003, Raynaud et al 2011), while other hepatoblasts gradually differentiate into mature hepatocytes. It has been shown that oncostatin M (OSM) promotes hepatic maturation (Kamiya et al 2001) During this phase, the liver bud transitions from a hematopoietic organ to a metabolic organ. Coexisting hematopoietic cells also play a significant role in the hepatic maturation process. For example, OSM is released from the hematopoietic cells and activates a JAK/Stat3 signaling pathway via the gp130 receptor (Ito et al 2000, Kamiya et al 1999), and intrahepatic structures are organized by ED15. The final maturation of the liver is a gradual process and continues into the postnatal period. Many hepatic enzymes such as cytochrome P450s shift from a fetal form to a mature form during the postnatal period.

\section{Hepatic differentiation of pluripotent stem cells}

Currently hepatic differentiation strategies from pluripotent stem cells can be classified into three approaches; 1) via formation of spontaneous embryoid body (EB), 2) co-culture with supporter cells, and 3) directed hepatic differentiation via stepwise stimulation by defined growth factors. 


\subsection{Embryoid body formation and spontaneous hepatic differentiation}

Mouse ESCs aggregate in suspension to form spheroid clumps of cells called embryoid bodies (EBs). Removal of leukemia inhibitory factor (LIF) induces spontaneous differentiation into three germ layers (Itskovitz-Eldor et al 2000). Chinzei et al reported that AFP and albumin gene expressions were detected in EBs after 9 days and 12 days, respectively, without additional exogenous growth factors (Chinzei et al 2002). However, the spontaneous differentiation of hepatocytes in EBs is inefficient (usually under 10\%) and is highly cell line dependent (Lavon \& Benvenisty 2005, Schwartz et al 2005, Shirahashi et al 2004). To increase the ratio of hepatic cells in the EBs, differentiation can be directed by exposure to exogenous growth factors. Hamazaki and colleagues demonstrated that the combination and consecutive supplementation of FGF, HGF, OSM, and dexamethasone efficiently induced hepatic differentiation (Hamazaki et al 2001). In regards to human ESCs, hepatic induction using the EB formation approach was reported by Schuldiner and colleagues (Schuldiner et al 2000). These studies with EB formation provided evidence that mouse and human pluripotent stem cells were able to differentiate to the hepatic lineage in vitro. The 3D structure of EBs has an advantage over the $2 \mathrm{D}$ culture system in further inducing functional maturation. However, the uncontrolled heterogeneous cell populations in EBs and the variation in size and morphology prohibit further clinical applications.

\subsection{Co-culture of pluripotent stem cells with supporter cells}

Another approach for hepatic differentiation is providing in vivo-like supplements including cytokines, growth factors, and extracellular matrixes. These elements can be provided by coculturing appropriate supporter cells, such as hepatic mesenchymal cells. A co-culture strategy for hepatic differentiation was first applied using Thy1-positive mesenchymal cells derived from mouse fetal liver (Ishii et al 2005). An enhanced green fluorescent protein (EGFP)-AFP labeling system was used to isolate hepatic lineage committed ES-derived cells, which were subsequently co-cultured with the Thy1 positive mesenchymal cells. Several late-phase hepatic markers such as tyrosine amino transferase, tryptophan 2,3-dioxygenase, and glucose-6phosphatase were expressed in the co-cultured ES-derived hepatocytes. Fair et al reported that co-cultured mESCs with chick embryonic cardiac mesoderm cells expressed mesendoderm genes, Sox17 $\alpha$, HNF3 $\beta$, GATA4, after 24 hours (Fair et al 2003). They also demonstrated that the xenogeneic cell-to-cell contact between mESCs and the chick cells, apart from providing cytokines/growth factors, may also provide signals via direct cell-to-cell interaction. In contrast, Saito et al demonstrated that diffusible factors from mouse fetal liver-derived cells were sufficient to stimulate hepatic differentiation of cynomolgus monkey ES cells (Saito et al 2006). They also demonstrated that induction of hepatic differentiation utilizing the co-culture system was faster than chemical/growth factor induction. Soto-Gutierrez et al combined a coculture system of human liver nonparenchymal cell lines with growth factors. This protocol resulted in the successful derivation of $70 \%$ albumin positive cells from mESCs (Soto-Gutierrez et al 2007). These data indicate the feasibility of the co-culture system for inducing hepatic differentiation from pluripotent stem cells. However, it might be difficult to reproduce hepatic differentiation by co-culturing with primary cells as the quality and the secreted factors are uncertain. Moreover, the contamination of the supporter cells and the difficulty in the scale-up of hepatocyte production are issues that hamper clinical applications.

\subsection{Guided hepatic differentiation with specific factors}

The in vitro developmental capability of ES cells has been shown with spontaneous differentiation with EB formation. The co-culture studies indicate that exogenous signals 
could induce hepatic differentiation. As described in section 2, extensive developmental biology studies have uncovered the pathways controlling hepatogenesis. To mimic the sequential stimulation of in vivo hepatogenesis, various combinations of stepwise growth factor stimulation strategies have been tested.

The critical first step is to efficiently induce definitive endoderm (DE) commitment of ESCs. Based on researches of mesendoderm and definitive endoderm differentiation in rodent and Xenopus, it was reasonable to expect that a high concentration of Nodal is key to the induction of definitive endoderm differentiation (Schier 2003). In most studies, a high dose of Activin A was used as a substitute for Nodal. Activin shares the same receptors (ActRII and ALK4) with Nodal but does not require the association of Cripto to initiate the Nodal/Smad2 signaling pathway (Strizzi et al 2005). After a few days of Activin treatment, most of the ES cells express definitive endoderm genes (Sox17 and Foxa2), while mesoderm, pluripotency and the extraembryonic endoderm genes are down regulated (D'Amour et al 2005, Kubo et al 2004). Further studies indicate that generation of hESC-DE requires two conditions: signaling by Activin/Nodal family members and the release from inhibitory signals generated by PI3K through insulin/IGF (McLean et al 2007). In this approach, using a high-density monolayer culture, pluripotent stem cells are cultured in a feeder cell-free system and mesendoderm differentiation is induced by a defined serum-free medium, supplemented with high-dose of Activin A (e.g. 100ng/ml) (Yoshie et al 2010).

The signaling pathways regulating foregut formation can be recapitulated in cell culture by the addition of specific growth factors such as FGFs and BMPs. A number of groups have used this combination to generate hepatic cells (Dan \& Yeoh 2008, Ochiya et al 2009). The endoderm specification stage is followed by HGF stimulation to expand the hepatoblast population (LaBrecque 1994). Hepatic maturation is normally regulated and promoted by some combination of OSM and Dexamethasone. (Agarwal et al 2008, Baharvand et al 2008, Cai et al 2007, Soto-Gutierrez et al 2006b, Teratani et al 2005).

Hay and colleagues introduced a similar stepwise induction concept, except using chemicals to induce hepatic differentiation in ES and iPS cells (Hay et al 2008a, Hay et al 2008b, Sullivan et al 2010). A combination of Activin A and the histone deacetylase inhibitors (HDI), sodium butyrate, were utilized for the definitive endoderm induction and 1\% DMSO for further hepatic specification (Hay et al 2008b). Although the effect of butyrate for inducing differentiation has been known for a long time (Leder \& Leder 1975), the role of HDI in the hepatic differentiation process was not totally elucidated. McLean showed that a combination of Activin and a PI3K inhibitor is more efficient to induce DE differentiation (McLean et al 2007). Recent progress on studies in signal transduction pathways has led researchers to control not only the initiation of signal transduction by adding exogenous growth factors, but also the regulation of intracellular signaling to induce hepatic differentiation in a more precise and efficient manner. Touboul et al used the PI3K inhibitor, LY294002, for DE induction and activin receptor-like kinase (ALK) 5 inhibitor, SB431542, for hepatic specification. Currently, these protocols still require combinations with recombinant growth factors. Since mass production of these recombinant proteins are cost prohibitive, a totally defined chemical protocol would be ideal for a large-scale hepatocyte production.

Although hepatic differentiation protocols are now more sophisticated, fully differentiated stem cell-derived hepatocytes that possess identical hepatic functions to primary adult hepatocytes have yet to be produced. Using a unique primary hepatocyte culture system, Michalopoulos's group demonstrated that a combination of dexamethasone, HGF, and EGF was required for formation of liver-like tissue. Dexamethasone induces expression of both 
HNF4 $\alpha$ and C/EBP- $\alpha$, essential transcription factors for hepatocyte differentiation, while HGF and EGF induce members of the TGF- $\beta$ family and HNF6 $\beta$, which are essential for maintenance of hepatic functions (Michalopoulos et al 2003). Although this unique culture system has not been tested with stem cell-derived hepatic cells, this combination and culture system may be essential to achieve further hepatic maturation.

\section{Enrichment strategies of stem cell derived hepatocytes}

Despite utilizing these well-designed differentiation protocols on mouse and human ES cells, hepatic induction from pluripotent stem cells results in mixtures with non-hepatic cells. Generally speaking, in the areas of stem cell-derived cell studies, there has not been a differentiation protocol that is able to induce $100 \%$ of this desired target cells based upon current technologies. This is one of the issues that is hindering further clinical development. Particularly in the use of pluripotent stem cells, contamination with undifferentiated cells is one of the biggest concerns due to their tumorigenic potential (Ben-David \& Benvenisty 2011, Dressel et al 2008). Therefore, further investigations will be necessary to obtain clinically applicable stem cell-derived hepatocytes. One of the approaches is to develop techniques that allow for isolation and purification of specific hepatic subtypes.

For basic research, it is common to use genetic selection techniques. Under this strategy, undifferentiated pluripotent stem cells are genetically modified to carry either a reporter gene, usually a green fluorescence protein (EGFP) gene or an antibiotic resistance gene under the transcriptional control of a hepatic-promoter such as alpha-fetoprotein (Yin et al 2002). The transgenic cells are then induced to differentiate and subsequently selected based on the activation of the hepatocyte-specific promoter. The major disadvantage of this approach is the risks associated with the genetic modification which may lead to insertional oncogenesis. In addition, these transcriptional markers are also common to immature hepatocytes. It is, therefore difficult to designate one gene as a definitive single marker of hepatic differentiation.

An endogenously expressed surface marker, asialoglycoprotein receptor (ASGPR), has been proposed as a cell surface marker for functional hepatocytes ( $\mathrm{Li}$ et al 2008, Treichel et al 1995). Recent studies have utilized ASGPR to identify mature hepatic cells from a mixed population of fetal hepatocytes (Ring et al 2010). ASGPR is a transmembrane hepatocellular surface carbohydrate binding glycoprotein that lacks terminal sialic acid residues (=asialoglycoproteins). Characterization of the ASGPR has revealed its functional role in the binding, internalization and transport of a wide range of glycoproteins in a selective manner via the process of receptor-mediated endocytosis. The expression of the ASGPR has been clinically correlated to loss of hepatic functions in liver diseases associated with cancer, viral hepatitis, and cirrhosis. Basma et al enriched hESC-derived hepatic cells using the ASGPR marker (Basma et al 2009). Although the G6Pase, albumin, and TAT mRNA expressions were dramatically improved by this enrichment step, mRNA expression of both Oct4 and AFP were still detectable. This data indicates that a single enrichment step could not completely eliminate the undifferentiated stem cell or the progenitor cell contamination.

Kumashiro et al used a silica-based colloidal medium (Percoll) and PECAM-1 antibodies to separate mESCs-derived hepatocytes from Oct 4 positive undifferentiated cells. The ESderived hepatocytes were transplanted into the CCl4-injured mouse liver and this led to improved liver function. Importantly, unlike unselected ES-derived hepatocytes, the enriched ES-derived hepatocytes did not develop teratomas in the recipients' liver (Kumashiro et al 2005). 
Conclusively, the hepatic enrichment studies demonstrate the advantages of selecting hepatic cells from mixed ES-derived cell population. However, there is to date, no single standard technology to achieve sufficient hepatocyte enrichment or non-hepatic cell exclusion. The influence of other cell types on hepatic differentiation is one aspect that requires further studies. Non-hepatic cells such as cholangiocyte contamination may have a positive influence for further maturation in stem cell-derived hepatic cells. For future clinical applications, genetic modification of stem cell will not be acceptable. Although the ASGPR enrichment protocol is promising, the need for a large quantity of antibody remains a substantial financial burden for large-scale production of stem cell-derived hepatocytes. Thus, additional investigations are needed to find novel strategies to enrich clinically viable stem cell-derived hepatocytes.

\section{Characteristics of pluripotent stem cell derived hepatocytes}

One of the difficulties for stem cell research is the interpretation of in vitro data on the extent of terminal differentiation. Since human primary hepatocytes lose their hepatic functions in vitro within a week after their isolation, it is clearly a challenge to induce full maturation status equivalent to that of adult hepatocytes in stem cell-derived hepatocytes in vitro. With this in mind, the in vitro evaluation for hepatic differentiation has to be undertaken very carefully using multi-pronged approaches. The evaluation should be conducted at 1) the transcription level, 2) the translation level, 3) performing biochemical (in vitro) functional tests, as well as 4) in vivo functional assays.

\subsection{Transcriptional evaluation. Hepatic marker genes expression}

Many genes have been proposed as hepatocyte-specific genes. The most commonly cited genes are; albumin, alpha-fetoprotein (AFP), cytokeratin-18, glucose-6-phosphatase (G6P), phosphoenolpyruvate carboxykinase (PEPCK), alpha-1-antitrypsin (A1AT), bilirubin, uridine diphosphate-glucuronosyltransferase, coagulation factor VII. However, some of these are also expressed in other tissues such as extra-embryonic yolk sac. AFP, for example, is expressed in both the liver and the yolk sac. Therefore, AFP expression needs to be demonstrated along with definitive endoderm marker genes, Sox17 and CXCR4. Transcriptome studies on mouse liver development have revealed that the expression patterns of these hepatic markers are dramatically altered during hepatogenesis. For instance, Jochheim et al. demonstrated that HNF4 $\alpha$ gene expression peaked on ED11.5 and decreased until ED13.5, after which, it gradually increased but its levels were not as high as at ED11.5 (Jochheim et al 2003). Therefore, quantitative RT-PCR data must be carefully interpreted, as a downregulation of HNF $4 \alpha$ mRNA expression could still be an indication of increased hepatocyte maturation. Genes encoding cytochrome P-450 (CYP)-7A1, bilirubin, uridine diphosphate-glucuronosyltransferase, coagulation factor VII, and asialoglycoprotein receptors are considered late phase hepatic marker genes and are not expressed in the yolk sac. Therefore, these genes could be useful as markers for mature hepatocytes. In contrast, G6P, CYP3A4 and PEPCK are also deemed late-phase marker genes, however, their expression is not liver specific. CYP7A1 is a member of the cytochrome P450 superfamily of enzymes. This liver specific endoplasmic reticulum membrane protein is involved in the cholesterol catabolic pathway, which converts cholesterol to bile acids. Other CYP enzymes are responsible for oxidative metabolism of most therapeutic drugs. Therefore, it is important to demonstrate the expression of these genes in the stem cell-derived hepatic cells 
for drug testing. Among the CYP enzymes, 3A4, 1A2, 2C19, 2D6, are dominant players for drug metabolism in human liver.

Ideally the gene expression levels in stem cell-derived hepatic cell at the end of the differentiation protocol should be comparable to that of an adult hepatocyte. Concurrently, evaluations for non-hepatocyte specific genes to determine the extent of differentiation to specific hepatic lineage should also be performed.

With regards to the development of drug metabolizing enzymes such as CYP genes, both the pattern and the level of expressions are important. Many metabolic and detoxifying enzymes are expressed at significant levels only after birth. Therefore, the gene expression ratio of the fetal form to the adult form could be used as a determinant of the status of hepatic maturation. For example, fetal liver cells express CYP3A7, a fetal form of CYP3A4. Higher 3A4/3A7 ratio indicates increased hepatic maturation of stem cell-derived hepatic cells (Ek et al 2007, Miki et al 2011).

\subsection{Translational evaluation. Hepatic marker proteins expression}

Gene expression does not necessarily translate to protein production and activity. Using a hepatic differentiation protocol, Hay et al demonstrated that Oct4 protein was undetectable after the second day, while Oct 4 mRNA remains detectable until day 11 of the protocol. Along the same vein, albumin mRNA expression was observed at day 11 but albumin protein was detected only starting at day 15 (Hay et al 2008b). Therefore, immunohistochemistry and/or Western blot analyses must be performed to verify the expression of key proteins at the end of any differentiation protocol. AFP, Albumin, A1AT, and cytokeratins $(8,18,19)$ are common proteins that were used in many reports. As mentioned in section 4, some cell surface marker proteins (e.g. ASGPR) are also important.

\subsection{Biochemical functional assay}

Demonstration of albumin production and secretion from stem cell-derived hepatic cells is the gold standard assay to demonstrate functional protein synthesis. In the human body, albumin is the most abundant protein in serum and is produced specifically by the liver. Therefore, serum albumin has been used as an indicator to evaluate liver function in a clinical setting. Although albumin production and secretion are essential, it is however insufficient to use this as a marker for stem cell-derived hepatic cells. It has been shown the albumin gene is expressed at a relatively early stage of hepatogenesis, and furthermore, visceral endoderm cells such as yolk sac cells also produce albumin (Meehan et al 1984). Therefore, albumin production from stem cell-derived hepatic cells must be further supported through a combination of other assays.

The ability to metabolize ammonia is also a standard assay to evaluate hepatic detoxification function. In vivo, ammonia is a metabolic product generated from dietary amino acids, and $80-90 \%$ of ammonia is converted into urea by hepatocytes through the urea cycle. To test this function in vitro, excess amount of ammonium chloride is added to the culture medium (ammonia challenge). Ammonia clearance or urea production can then be measured as functional readout of the assay. Since precise parameter adjustment for measuring ammonia level in culture media is difficult, the standard protocol is measuring urea concentration in the supernatant via the enzymatic urease method. A pitfall in this assay is the possibility of arginase leakage from damaged cells due to the excess ammonium chloride, which could produce urea independently from the urea cycle activity. Therefore, the acquisition of urea metabolism function should be further confirmed by the expression of key enzymes in the 
urea cycle, such as arginase I (ARG1), argininosuccinate lyase (ASL), argininosuccinate synthetase 1 (ASS1), carbamoyl-phosphate synthetase 1 (CPS1), and ornithine carbamoyltransferase (OTC) (Mavri-Damelin et al 2008, Miki et al 2011).

To meet the demand for pharmaco-toxicological applications, demonstration of activities of xenobiotic-metabolizing phase I and phase II enzymes and phase III transporters must be satisfied (Xu et al 2005). To evaluate phase I activities, CYP-dependent monooxygenase activity assays; 7-ethoxycoumarin-O-deethylase (ECOD assay) (Lubet et al 1985), 7ethoxyresorufin-O-deethylase (EROD assay), and specific oxidation of testosterone are commonly used. In measuring phase II activities, glucuronosyltransferase activity and sulfotransferase activity toward p-nitrophenol, and glutathione S-transferase activity are commonly used. Functional assays for phase III transporters have yet to be standardized. Measurement of fluorescent protein conjugated bile acid could be useful to evaluate one of the phase III transporters, i.e. the bile salt export pump (BSEP/ABCB11), for activity in stem cell-derived hepatocytes (Yamaguchi et al 2010).

\subsection{In vivo analysis}

These in vitro hepatic functional assays are essential and useful. However, the most definitive proof for the functionality of stem cell-derived hepatic cells would be the demonstration of hepatic engraftment in vivo using animal models (Soto-Gutierrez et al 2006a, Yamamoto et al 2003). It would be ideal if stem cell-derived hepatic cells could improve survival rates in lethal disease models. Transgenic mouse models of congenital liver diseases would be candidates for such assays. The fumarylacetoacetate hydrolase (FAH) deficiency mouse model (Lagasse et al 2000) and urokinase-type plasminogen activator-transgenic SCID mice (Tateno et al 2004) have been previously and provide a means to test stem cell-derived hepatocytes in a liver transplantation setting. Unfortunately such animal models are not widely available and also require significant technical expertise to perform hepatocyte transplantation in neonatal animals.

Nevertheless, whether human or rodent, primary hepatocytes tend to lose their differentiated characteristics in culture. One question that arises is whether the stem cellderived hepatic cells have to be fully differentiated in vitro. It is anticipated that stem cellderived hepatic progenitor cells spontaneously differentiate to fully mature hepatocytes in their correct endogenous environment. Once hepatic lineage commitment is confirmed, stem cell-derived hepatic progenitor cells could be an acceptable source for cell replacement therapy. The endogenous mouse liver environment is suitable to test this hypothesis. It is therefore extremely important to establish standard animal models that are easy to experiment with, and also widely available for stem cell-derived hepatic cell transplantation.

\section{Conclusion and future perspectives}

Hepatic differentiation is a sequential dynamic event that involves various types of cells and complex signaling networks. Although the signaling pathways and growth factors that are involved in definitive endoderm specification have been well documented, only portions of the mechanisms involved in the human hepatogenic development have been defined. Therefore, the goal of inducing directed differentiation of pluripotent stem cells toward hepatocytes remains a big challenge. A number of differentiation protocols have been described to generate hepatocytes from pluripotent stem cells. Collectively, various hepatic 
differentiation studies demonstrate how the exposure of various growth factors to pluripotent stem cells, with the appropriate timing and doses, is essential for directing the differentiation process from early mesendoderm via definitive endoderm towards more functionally mature hepatocytes. Based on the recent advances in the field of developmental biology, hepatic differentiation protocols have been modified to provide more than $70 \%$ albumin positive cells from mESCs (Soto-Gutierrez et al 2007) and 35\% of ASGPR positive cells from hESCs (Touboul et al 2010). It appears that iPS cells possess a similar capacity to hES cells to generate hepatocytes using similar differentiation protocols (Sullivan et al 2010). It must be noted that the stem cell-derived hepatocytes described to date generally exhibit fetal hepatocyte-like gene expression profiles and immature functional characteristics compared to authentic adult primary hepatocytes. Recent finding suggested that a 3D dynamic bioreactor culture system which provides an in vivo-like culture environment induced teratoma-like multi-directional differentiation of human ESCs (Gerlach et al 2010). When a hepatic differentiation protocol was applied in this system, the 3D dynamic culture system induced further hepatic maturation, including tissue-like structure formation (Miki et al 2011). Although the superiority of the culture conditions in the 3D dynamic culture system has been clearly demonstrated, it is difficult to determine which parameters are critical for this advantage in hepatic maturation. Using matrigel or collagen gel, it has been shown that static 3D culture conditions prolong hepatic function of primary hepatocytes (Kono et al 1997). It has been proposed that the 3D structure allows more physiological cellto-cell interactions, and induces polarity in hepatocytes (Haouzi et al 2005). Baharvand et al demonstrated that hESCs are more efficiently differentiated to hepatic cells under static 3D culture conditions than conventional 2D culture conditions (Baharvand et al 2008).

Dynamic culture conditions are, not surprisingly, more advantageous than static culture conditions (Vinci et al 2011). Unlike static cultures, the dynamic culture system provides continuous and gradual medium change under controlled oxygen tension and temperature. Taken together, the dynamic 3D culture system can provide a more physiological and homeostatic environment that could be favorable for stem cell-derived hepatocyte maturation. The continuous supply of fresh medium via nano-size porous hollow fibers also provides micro steady flow around the cells (Gerlach et al 2010) and low shear stress that could further stimulate maturation signals through sensory systems (e.g. cilia) on the polarized hepatic cells (Decaens et al 2008). Furthermore, it is noteworthy that in the human body, the liver passively but dynamically moves with the movements of diaphragm. In addition to the oxygen concentration in the blood flow, such movement could be a factor to induce rapid postnatal hepatic maturation events such as cytochrome isotype switching from CYP3A7 to 3A4.

As reviewed, the current differentiation protocols demonstrated the feasibility of hepatic cell production from pluripotent stem cells. Further optimization will be required to better define hepatic differentiation protocols and improved culture conditions to obtain fully differentiated functional hepatocytes in vitro. On the other hand, for cell replacement therapy applications, such in vitro full maturation may not be essential. Both fetal and adult hepatocytes demonstrated bilirubin conjugating activity in the Gunn rat after cell transplantation (Borel-Rinkes et al 1992). Hepatic progenitor cells could mature in the endogenous hepatic environment and thereby provide therapeutic effects to patients. The direction of research for this goal will be generating hepatic lineage committed cells in vitro, establishing an appropriate enrichment protocol, and critically evaluating the efficacy and safety of these cells in animal models. 
In conclusion, the promise of pluripotent stem cells for the generation of hepatocytes and with further investigations will eventually lead us to a more in-depth understanding of mechanisms of hepatogenesis and hepatic maturation. The widespread utility of pluripotent stem cell-derived functional hepatocytes for basic research and pharmaceutical applications, could also become a reality. In the future, stem cell-derived hepatocytes are anticipated to have an enormous impact on the treatment of liver disease.

\section{References}

Agarwal S, Holton KL, Lanza R. 2008. Efficient differentiation of functional hepatocytes from human embryonic stem cells. Stem Cells 26: 1117-27

Alison M, Sarraf C. 1998. Hepatic stem cells. J Hepatol 29: 676-82

Baharvand H, Hashemi SM, Shahsavani M. 2008. Differentiation of human embryonic stem cells into functional hepatocyte-like cells in a serum-free adherent culture condition. Differentiation 76: 465-77

Basma H, Soto-Gutierrez A, Yannam GR, Liu L, Ito R, et al. 2009. Differentiation and transplantation of human embryonic stem cell-derived hepatocytes. Gastroenterology 136: 990-9

Ben-David U, Benvenisty N. 2011. The tumorigenicity of human embryonic and induced pluripotent stem cells. Nat Rev Cancer 11: 268-77

Birchmeier C, Birchmeier W, Gherardi E, Vande Woude GF. 2003. Met, metastasis, motility and more. Nat Rev Mol Cell Biol 4: 915-25

Blouin A, Bolender RP, Weibel ER. 1977. Distribution of organelles and membranes between hepatocytes and nonhepatocytes in the rat liver parenchyma. A stereological study. J Cell Biol 72: 441-55

Borel-Rinkes IH, Bijma AM, Kappers WA, Sinaasappel M, Hoek FJ, et al. 1992. Evidence of metabolic activity of adult and fetal rat hepatocytes transplanted into solid supports. Transplantation 54: 210-4

Cai J, Zhao Y, Liu Y, Ye F, Song Z, et al. 2007. Directed differentiation of human embryonic stem cells into functional hepatic cells. Hepatology 45: 1229-39

Calmont A, Wandzioch E, Tremblay KD, Minowada G, Kaestner KH, et al. 2006. An FGF response pathway that mediates hepatic gene induction in embryonic endoderm cells. Dev Cell 11: 339-48

Chinzei R, Tanaka Y, Shimizu-Saito K, Hara Y, Kakinuma S, et al. 2002. Embryoid-body cells derived from a mouse embryonic stem cell line show differentiation into functional hepatocytes. Hepatology 36: 22-9

D'Amour KA, Agulnick AD, Eliazer S, Kelly OG, Kroon E, Baetge EE. 2005. Efficient differentiation of human embryonic stem cells to definitive endoderm. Nat Biotechnol 23: 1534-41

Dan YY, Yeoh GC. 2008. Liver stem cells: a scientific and clinical perspective. J Gastroenterol Hepatol 23: 687-98

Davila JC, Cezar GG, Thiede M, Strom S, Miki T, Trosko J. 2004. Use and application of stem cells in toxicology. Toxicol Sci 79: 214-23

Decaens C, Durand M, Grosse B, Cassio D. 2008. Which in vitro models could be best used to study hepatocyte polarity? Biol Cell 100: 387-98 
Dessimoz J, Opoka R, Kordich JJ, Grapin-Botton A, Wells JM. 2006. FGF signaling is necessary for establishing gut tube domains along the anterior-posterior axis in vivo. Mech Dev 123: 42-55

Dressel R, Schindehutte J, Kuhlmann T, Elsner L, Novota P, et al. 2008. The tumorigenicity of mouse embryonic stem cells and in vitro differentiated neuronal cells is controlled by the recipients' immune response. PLoS One 3: e2622

Duncan SA. 2003. Mechanisms controlling early development of the liver. Mech Dev 120: 19-33

Ek M, Soderdahl T, Kuppers-Munther B, Edsbagge J, Andersson TB, et al. 2007. Expression of drug metabolizing enzymes in hepatocyte-like cells derived from human embryonic stem cells. Biochem Pharmacol 74: 496-503

Fair JH, Cairns BA, Lapaglia M, Wang J, Meyer AA, et al. 2003. Induction of hepatic differentiation in embryonic stem cells by co-culture with embryonic cardiac mesoderm. Surgery 134: 189-96

Fox IJ, Chowdhury JR, Kaufman SS, Goertzen TC, Chowdhury NR, et al. 1998. Treatment of the Crigler-Najjar syndrome type I with hepatocyte transplantation. $N$ Engl J Med 338: 1422-6

Freeman RB, Jr., Wiesner RH, Harper A, McDiarmid SV, Lake J, et al. 2002. The new liver allocation system: moving toward evidence-based transplantation policy. Liver Transpl 8: 851-8

Gerlach JC, Hout M, Edsbagge J, Bjorquist P, Lubberstedt M, et al. 2010. Dynamic 3D culture promotes spontaneous embryonic stem cell differentiation in vitro. Tissue Eng Part C Methods 16: 115-21

Gerlach JC, Zeilinger K, Patzer Ii JF. 2008. Bioartificial liver systems: why, what, whither? Regen Med 3: 575-95

Ghodsizadeh A, Taei A, Totonchi M, Seifinejad A, Gourabi H, et al. 2010. Generation of liver disease-specific induced pluripotent stem cells along with efficient differentiation to functional hepatocyte-like cells. Stem Cell Rev 6: 622-32

Gilchrist ES, Plevris JN. 2010. Bone marrow-derived stem cells in liver repair: 10 years down the line. Liver Transpl 16: 118-29

Goodell MA. 2003. Stem-cell "plasticity": befuddled by the muddle. Curr Opin Hematol 10: 208-13

Hamazaki T, Iiboshi Y, Oka M, Papst PJ, Meacham AM, et al. 2001. Hepatic maturation in differentiating embryonic stem cells in vitro. FEBS Lett 497: 15-9

Haouzi D, Baghdiguian S, Granier G, Travo P, Mangeat P, Hibner U. 2005. Threedimensional polarization sensitizes hepatocytes to Fas/CD95 apoptotic signalling. J Cell Sci 118: 2763-73

Hay DC, Fletcher J, Payne C, Terrace JD, Gallagher RC, et al. 2008a. Highly efficient differentiation of hESCs to functional hepatic endoderm requires ActivinA and Wnt3 $\alpha$ signaling. Proc Natl Acad Sci U S A 105: 12301-6

Hay DC, Zhao D, Fletcher J, Hewitt ZA, McLean D, et al. 2008b. Efficient differentiation of hepatocytes from human embryonic stem cells exhibiting markers recapitulating liver development in vivo. Stem Cells 26: 894-902

Ishii T, Yasuchika K, Fujii H, Hoppo T, Baba S, et al. 2005. In vitro differentiation and maturation of mouse embryonic stem cells into hepatocytes. Exp Cell Res 309: 68-77 
Ito Y, Matsui T, Kamiya A, Kinoshita T, Miyajima A. 2000. Retroviral gene transfer of signaling molecules into murine fetal hepatocytes defines distinct roles for the STAT3 and ras pathways during hepatic development. Hepatology 32: 1370-6

Itskovitz-Eldor J, Schuldiner M, Karsenti D, Eden A, Yanuka O, et al. 2000. Differentiation of human embryonic stem cells into embryoid bodies compromising the three embryonic germ layers. Mol Med 6: 88-95

Jochheim A, Cieslak A, Hillemann T, Cantz T, Scharf J, et al. 2003. Multi-stage analysis of differential gene expression in BALB/C mouse liver development by high-density microarrays. Differentiation 71: 62-72

Jung J, Zheng M, Goldfarb M, Zaret KS. 1999. Initiation of mammalian liver development from endoderm by fibroblast growth factors. Science 284: 1998-2003

Kamiya A, Kinoshita T, Ito Y, Matsui T, Morikawa Y, et al. 1999. Fetal liver development requires a paracrine action of oncostatin $M$ through the gp130 signal transducer. Embo J 18: 2127-36

Kamiya A, Kinoshita T, Miyajima A. 2001. Oncostatin M and hepatocyte growth factor induce hepatic maturation via distinct signaling pathways. FEBS Lett 492: 90-4

Kono Y, Yang S, Roberts EA. 1997. Extended primary culture of human hepatocytes in a collagen gel sandwich system. In Vitro Cell Dev Biol Anim 33: 467-72

Kubo A, Shinozaki K, Shannon JM, Kouskoff V, Kennedy M, et al. 2004. Development of definitive endoderm from embryonic stem cells in culture. Development 131: 1651-62

Kumashiro Y, Asahina K, Ozeki R, Shimizu-Saito K, Tanaka Y, et al. 2005. Enrichment of hepatocytes differentiated from mouse embryonic stem cells as a transplantable source. Transplantation 79: 550-7

LaBrecque D. 1994. Liver regeneration: a picture emerges from the puzzle. Am J Gastroenterol 89: $586-96$

Lagasse E, Connors H, Al-Dhalimy M, Reitsma M, Dohse M, et al. 2000. Purified hematopoietic stem cells can differentiate into hepatocytes in vivo. Nat Med 6: 1229-34

Lavon N, Benvenisty N. 2005. Study of hepatocyte differentiation using embryonic stem cells. J Cell Biochem 96: 1193-202

Leder A, Leder P. 1975. Butyric acid, a potent inducer of erythroid differentiation in cultured erythroleukemic cells. Cell 5: 319-22

Lemaigre F, Zaret KS. 2004. Liver development update: new embryo models, cell lineage control, and morphogenesis. Curr Opin Genet Dev 14: 582-90

Lemaigre FP. 2003. Development of the biliary tract. Mech Dev 120: 81-7

Li Y, Huang G, Diakur J, Wiebe LI. 2008. Targeted delivery of macromolecular drugs: asialoglycoprotein receptor (ASGPR) expression by selected hepatoma cell lines used in antiviral drug development. Curr Drug Deliv 5: 299-302

Lubet RA, Mayer RT, Cameron JW, Nims RW, Burke MD, et al. 1985. Dealkylation of pentoxyresorufin: a rapid and sensitive assay for measuring induction of cytochrome(s) P-450 by phenobarbital and other xenobiotics in the rat. Arch Biochem Biophys 238: 43-8

Mavri-Damelin D, Damelin LH, Eaton S, Rees M, Selden C, Hodgson HJ. 2008. Cells for bioartificial liver devices: the human hepatoma-derived cell line C3A produces urea but does not detoxify ammonia. Biotechnol Bioeng 99: 644-51 
McLean AB, D'Amour KA, Jones KL, Krishnamoorthy M, Kulik MJ, et al. 2007. Activin a efficiently specifies definitive endoderm from human embryonic stem cells only when phosphatidylinositol 3-kinase signaling is suppressed. Stem Cells 25: 29-38

McLin VA, Rankin SA, Zorn AM. 2007. Repression of Wnt/beta-catenin signaling in the anterior endoderm is essential for liver and pancreas development. Development 134: 2207-17

Medine CN, Greenhough S, Hay DC. 2010. Role of stem-cell-derived hepatic endoderm in human drug discovery. Biochem Soc Trans 38: 1033-6

Meehan RR, Barlow DP, Hill RE, Hogan BL, Hastie ND. 1984. Pattern of serum protein gene expression in mouse visceral yolk sac and foetal liver. Embo J 3: 1881-5

Michalopoulos GK, Bowen WC, Mule K, Luo J. 2003. HGF-, EGF-, and dexamethasoneinduced gene expression patterns during formation of tissue in hepatic organoid cultures. Gene Expr 11: 55-75

Micsenyi A, Tan X, Sneddon T, Luo JH, Michalopoulos GK, Monga SP. 2004. Beta-catenin is temporally regulated during normal liver development. Gastroenterology 126: $1134-46$

Miki T, Ring A, Gerlach J. 2011. Hepatic differentiation of human embryonic stem cells is promoted by three-dimensional dynamic perfusion culture conditions. Tissue Eng Part C Methods 17: 557-68

Monga SP, Monga HK, Tan X, Mule K, Pediaditakis P, Michalopoulos GK. 2003. Betacatenin antisense studies in embryonic liver cultures: role in proliferation, apoptosis, and lineage specification. Gastroenterology 124: 202-16

Ochiya T, Yamamoto Y, Banas A. 2009. Commitment of stem cells into functional hepatocytes. Differentiation

Pelton RW, Saxena B, Jones M, Moses HL, Gold LI. 1991. Immunohistochemical localization of TGF beta 1, TGF beta 2, and TGF beta 3 in the mouse embryo: expression patterns suggest multiple roles during embryonic development. J Cell Biol 115: 1091-105

Raynaud P, Carpentier R, Antoniou A, Lemaigre FP. 2011. Biliary differentiation and bile duct morphogenesis in development and disease. Int J Biochem Cell Biol 43: 245-56

Rifkind RA, Chui D, Epler H. 1969. An ultrastructural study of early morphogenetic events during the establishment of fetal hepatic erythropoiesis. J Cell Biol 40: 343-65

Ring A, Gerlach J, Peters G, Pazin BJ, Minervini CF, et al. 2010. Hepatic Maturation of Human Fetal Hepatocytes in Four-Compartment Three-Dimensional Perfusion Culture. Tissue Eng Part C Methods

Roberts DJ. 2000. Molecular mechanisms of development of the gastrointestinal tract. Dev Dyn 219: 109-20

Rossi JM, Dunn NR, Hogan BL, Zaret KS. 2001. Distinct mesodermal signals, including BMPs from the septum transversum mesenchyme, are required in combination for hepatogenesis from the endoderm. Genes Dev 15: 1998-2009

Saito K, Yoshikawa M, Ouji Y, Moriya K, Nishiofuku M, et al. 2006. Promoted differentiation of cynomolgus monkey ES cells into hepatocyte-like cells by co-culture with mouse fetal liver-derived cells. World J Gastroenterol 12: 6818-27 
Schaffler A, Buchler C. 2007. Concise review: adipose tissue-derived stromal cells--basic and clinical implications for novel cell-based therapies. Stem Cells 25: 818-27

Schier AF. 2003. Nodal signaling in vertebrate development. Annu Rev Cell Dev Biol 19: 589-621

Schuldiner M, Yanuka O, Itskovitz-Eldor J, Melton DA, Benvenisty N. 2000. Effects of eight growth factors on the differentiation of cells derived from human embryonic stem cells. Proc Natl Acad Sci U S A 97: 11307-12

Schwartz RE, Linehan JL, Painschab MS, Hu WS, Verfaillie CM, Kaufman DS. 2005. Defined conditions for development of functional hepatic cells from human embryonic stem cells. Stem Cells Dev 14: 643-55

Shen MM. 2007. Nodal signaling: developmental roles and regulation. Development 134: 1023-34

Shirahashi H, Wu J, Yamamoto N, Catana A, Wege H, et al. 2004. Differentiation of human and mouse embryonic stem cells along a hepatocyte lineage. Cell Transplant 13: 197-211

Soto-Gutierrez A, Kobayashi N, Rivas-Carrillo JD, Navarro-Alvarez N, Zhao D, et al. 2006a. Reversal of mouse hepatic failure using an implanted liver-assist device containing ES cell-derived hepatocytes. Nat Biotechnol 24: 1412-9

Soto-Gutierrez A, Navarro-Alvarez N, Rivas-Carrillo JD, Chen Y, Yamatsuji T, et al. 2006b. Differentiation of human embryonic stem cells to hepatocytes using deleted variant of HGF and poly-amino-urethane-coated nonwoven polytetrafluoroethylene fabric. Cell Transplant 15: 335-41

Soto-Gutierrez A, Navarro-Alvarez N, Zhao D, Rivas-Carrillo JD, Lebkowski J, et al. 2007. Differentiation of mouse embryonic stem cells to hepatocyte-like cells by co-culture with human liver nonparenchymal cell lines. Nat Protoc 2: 347-56

Stenvers KL, Tursky ML, Harder KW, Kountouri N, Amatayakul-Chantler S, et al. 2003. Heart and liver defects and reduced transforming growth factor beta2 sensitivity in transforming growth factor beta type III receptor-deficient embryos. Mol Cell Biol 23: $4371-85$

Strizzi L, Bianco C, Normanno N, Salomon D. 2005. Cripto-1: a multifunctional modulator during embryogenesis and oncogenesis. Oncogene 24: 5731-41

Strom SC, Bruzzone P, Cai H, Ellis E, Lehmann T, et al. 2006. Hepatocyte transplantation: clinical experience and potential for future use. Cell Transplant 15 Suppl 1: S10510

Strom SC, Fisher RA, Thompson MT, Sanyal AJ, Cole PE, et al. 1997. Hepatocyte transplantation as a bridge to orthotopic liver transplantation in terminal liver failure. Transplantation 63: 559-69.

Strom SC, Jirtle RL, Jones RS, Novicki DL, Rosenberg MR, et al. 1982. Isolation, culture, and transplantation of human hepatocytes. J Natl Cancer Inst 68: 771-8

Sullivan GJ, Hay DC, Park IH, Fletcher J, Hannoun Z, et al. 2010. Generation of functional human hepatic endoderm from human induced pluripotent stem cells. Hepatology 51: $329-35$ 
Suzuki A, Zheng Y, Kondo R, Kusakabe M, Takada Y, et al. 2000. Flow-cytometric separation and enrichment of hepatic progenitor cells in the developing mouse liver. Hepatology 32: 1230-9

Tada S, Era T, Furusawa C, Sakurai H, Nishikawa S, et al. 2005. Characterization of mesendoderm: a diverging point of the definitive endoderm and mesoderm in embryonic stem cell differentiation culture. Development 132: 4363-74

Takahashi K, Tanabe K, Ohnuki M, Narita M, Ichisaka T, et al. 2007. Induction of pluripotent stem cells from adult human fibroblasts by defined factors. Cell 131: 861-72

Takahashi K, Yamanaka S. 2006. Induction of pluripotent stem cells from mouse embryonic and adult fibroblast cultures by defined factors. Cell 126: 663-76

Tateno C, Yoshizane Y, Saito N, Kataoka M, Utoh R, et al. 2004. Near completely humanized liver in mice shows human-type metabolic responses to drugs. Am J Pathol 165: 901-12

Teratani T, Yamamoto H, Aoyagi K, Sasaki H, Asari A, et al. 2005. Direct hepatic fate specification from mouse embryonic stem cells. Hepatology

Thomson JA, Itskovitz-Eldor J, Shapiro SS, Waknitz MA, Swiergiel JJ, et al. 1998. Embryonic stem cell lines derived from human blastocysts. Science 282: 1145-7.

Thuluvath PJ, Guidinger MK, Fung JJ, Johnson LB, Rayhill SC, Pelletier SJ. 2010. Liver transplantation in the United States, 1999-2008. Am J Transplant 10: 1003-19

Tian T, Meng AM. 2006. Nodal signals pattern vertebrate embryos. Cell Mol Life Sci 63: $672-85$

Touboul T, Hannan NR, Corbineau S, Martinez A, Martinet C, et al. 2010. Generation of functional hepatocytes from human embryonic stem cells under chemically defined conditions that recapitulate liver development. Hepatology 51: 1754-65

Treichel U, Schreiter T, Meyer zum Buschenfelde KH, Stockert RJ. 1995. High-yield purification and characterization of human asialoglycoprotein receptor. Protein Expr Purif 6: 251-5

Vincent SD, Dunn NR, Hayashi S, Norris DP, Robertson EJ. 2003. Cell fate decisions within the mouse organizer are governed by graded Nodal signals. Genes Dev 17: 1646-62

Vinci B, Duret C, Klieber S, Gerbal-Chaloin S, Sa-Cunha A, et al. 2011. Modular bioreactor for primary human hepatocyte culture: Medium flow stimulates expression and activity of detoxification genes. Biotechnol J 6: 554-64

Wagers AJ, Weissman IL. 2004. Plasticity of adult stem cells. Cell 116: 639-48

Xu C, Li CY, Kong AN. 2005. Induction of phase I, II and III drug metabolism/transport by xenobiotics. Arch Pharm Res 28: 249-68

Yamaguchi K, Murai T, Yabuuchi H, Hui SP, Kurosawa T. 2010. Measurement of bile salt export pump transport activities using a fluorescent bile acid derivative. Drug Metab Pharmacokinet 25: 214-9

Yamamoto H, Quinn G, Asari A, Yamanokuchi H, Teratani T, et al. 2003. Differentiation of embryonic stem cells into hepatocytes: biological functions and therapeutic application. Hepatology 37: 983-93 
Yin Y, Lim YK, Salto-Tellez M, Ng SC, Lin CS, Lim SK. 2002. AFP(+), ESC-derived cells engraft and differentiate into hepatocytes in vivo. Stem Cells 20: 338-46

Yoshie S, Shirasawa S, Yokoyama T, Kanoh Y, Takei S, et al. 2010. Lanford medium induces high quality hepatic lineage cell differentiation directly from mouse embryonic stem cell-derived mesendoderm. Biochem Biophys Res Commun 391: 1477-82

Zaret KS. 1996. Molecular genetics of early liver development. Annu Rev Physiol 58: 231-51

Zhao R, Duncan SA. 2005. Embryonic development of the liver. Hepatology 41: 956-67 


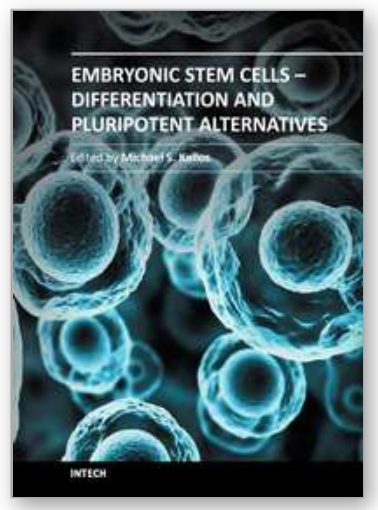

\author{
Embryonic Stem Cells - Differentiation and Pluripotent Alternatives \\ Edited by Prof. Michael S. Kallos
}

ISBN 978-953-307-632-4

Hard cover, 506 pages

Publisher InTech

Published online 12, October, 2011

Published in print edition October, 2011

The ultimate clinical implementation of embryonic stem cells will require methods and protocols to turn these unspecialized cells into the fully functioning cell types found in a wide variety of tissues and organs. In order to achieve this, it is necessary to clearly understand the signals and cues that direct embryonic stem cell differentiation. This book provides a snapshot of current research on the differentiation of embryonic stem cells to a wide variety of cell types, including neural, cardiac, endothelial, osteogenic, and hepatic cells. In addition, induced pluripotent stem cells and other pluripotent stem cell sources are described. The book will serve as a valuable resource for engineers, scientists, and clinicians as well as students in a wide range of disciplines.

\title{
How to reference
}

In order to correctly reference this scholarly work, feel free to copy and paste the following:

Toshio Miki (2011). Hepatic Differentiation of Human Embryonic and Induced Pluripotent Stem Cells for Regenerative Medicine, Embryonic Stem Cells - Differentiation and Pluripotent Alternatives, Prof. Michael S. Kallos (Ed.), ISBN: 978-953-307-632-4, InTech, Available from: http://www.intechopen.com/books/embryonicstem-cells-differentiation-and-pluripotent-alternatives/hepatic-differentiation-of-human-embryonic-andinduced-pluripotent-stem-cells-for-regenerative-medic

\section{INTECH}

open science | open minds

\section{InTech Europe}

University Campus STeP Ri

Slavka Krautzeka 83/A

51000 Rijeka, Croatia

Phone: +385 (51) 770447

Fax: +385 (51) 686166

www.intechopen.com

\section{InTech China}

Unit 405, Office Block, Hotel Equatorial Shanghai

No.65, Yan An Road (West), Shanghai, 200040, China

中国上海市延安西路65号上海国际贵都大饭店办公楼405单元

Phone: +86-21-62489820

Fax: +86-21-62489821 
(C) 2011 The Author(s). Licensee IntechOpen. This is an open access article distributed under the terms of the Creative Commons Attribution 3.0 License, which permits unrestricted use, distribution, and reproduction in any medium, provided the original work is properly cited. 